\title{
Spot diagnosis of intermittent gastrointestinal bleeding $\square$
}

\section{(ㄷ)(1) $\Theta$}

\author{
Authors \\ Judith E. Baars, Perveen Aslam, Arthur J. Kaffes, Payal Saxena \\ Institution \\ Royal Prince Alfred Hospital, Sydney, NSW, Australia \\ submitted 5.11.2017 \\ accepted after revision 20.2.2018 \\ Bibliography \\ DOI https://doi.org/10.1055/a-0629-8109 | \\ Endoscopy International Open 2018; 06: E1276-E1277 \\ (c) Georg Thieme Verlag KG Stuttgart · New York \\ ISSN 2364-3722
}

\section{Introduction}

Gastrointestinal bleeding is a common clinical problem seen by gastroenterologists. Most patients can be diagnosed and treated with endoscopic therapy through upper and lower gastrointestinal endoscopy. However, the source of bleeding cannot be identified in $10 \%$ to $15 \%$ of patients with upper gastrointestinal bleeding, either because the lesion is difficult to identify or obscured by retained blood at endoscopy or because the culprit lesion is healed by the time the endoscopy is performed. In this case report with video, we present a unique image of a rare, but important cause of gastrointestinal bleeding which often is missed due to its intermittent nature.

\section{Case report}

\section{Patient 1}

A 35-year-old woman with a history of recent nonsteroidal antiinflammatory use presented to our emergency department with melena. In the past months she had been feeling lethargic. No blood tests had been performed before she presented to our emergency department. Analysis at the time of presentation showed iron deficiency anaemia (Hb $58 \mathrm{~g} / \mathrm{L}$, ferritin $8 \mathrm{ug} / \mathrm{L}$ ). The patient was hemodynamically stable upon presentation. A gastroscopy was performed the next day and showed fresh blood in the second portion of duodenum although an obvious source could not be identified. Duodenoscopy was performed during the same session and confirmed the spot diagnosis of
Corresponding author

Dr. Payal Saxena, Suite G10, RPA Medical Centre, 100

Carillon Ave, Newtown, NSW 2042, Australia

Fax: +61295160778

psaxena1@jhmi.edu

\section{ABSTRACT}

Background and study aims In this case report with video, we present a unique image of a rare, but important cause of gastrointestinal bleeding which often is missed due to its intermittent nature. hemosuccus pancreaticus (HP) ( $\triangleright$ Fig. 1 and $\triangleright$ Video 1$)$. No other bleeding point was seen. Two other rare causes of an extraluminal source of gastrointestinal bleeding into the duodenum were considered, including hemobilia and a primary aortoenteric fistula. In this case, there was no reason to believe this patient had an aortic aneurysm. In addition, the video clearly demonstrates that the blood seemed to originate from the pancreatic orifice and the biliary orifice did not show any bleeding, which makes the diagnosis of hemobilia less likely. Urgent abdominal computed tomography (CT) angiography was normal, with no evidence of active bleeding or pseudoaneurysm. No mass lesion or other abnormalities were seen on endoscopic ultrasound (EUS) and magnetic resonance cholangiopancreatography. Amylase and lipase were also normal. The bleeding stopped spontaneously. At 1-year follow-up, the patient remained well without any further episodes of bleeding.

\section{Discussion}

$\mathrm{HP}$ is a rare cause of upper gastrointestinal bleeding (1:15000) characterized by fresh blood flow from the major papilla, first described in 1931 [1]. The term HP was coined in the 1970 s by Sandblom [2]. It usually presents with intermittent abdominal pain and gastrointestinal bleeding without hemodynamic compromise, which is thought to be due to its intermittent nature. HP is usually caused by pancreatitis, pseudoaneurysms, or pancreatic tumors [3]. Diagnosis can be challenging, as gastroscopy is often normal due to its intermittent course. The gold 


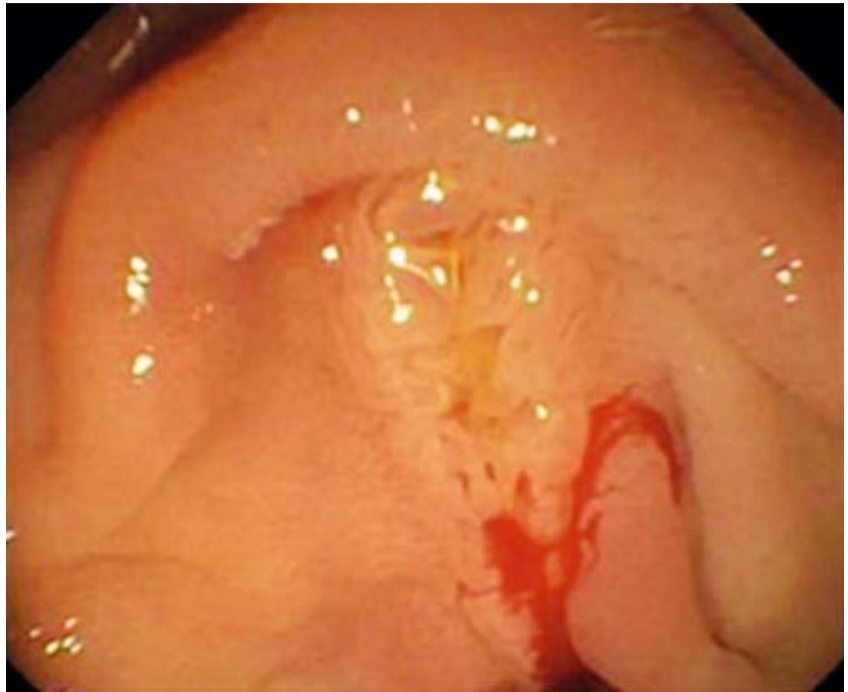

- Fig. 1 Fresh blood flowing from the major papilla, characteristic for hemosuccus pancreaticus.

standard for diagnosis is selective CT angiography, which can make the diagnosis in $96 \%$ of patients [4]. EUS has been described to be helpful in diagnosis as well [5]. In our case, radiologic imaging as well as EUS were all negative for unknown reasons.

In our patient, the bleeding resolved spontaneously. Often, selective embolization or surgery is indicated, depending on the underlying etiology [3].

\section{Conclusion}

In summary, we present a unique image of a rare, but important cause of gastrointestinal bleeding which often is missed due to its intermittent nature. With this video we emphasize that hemosuccus pancreaticus should always be considered as a cause of gastrointestinal blood loss.

\section{Acknowledgements}

Informed consent was obtained from the patient for the publication of her information and imaging.

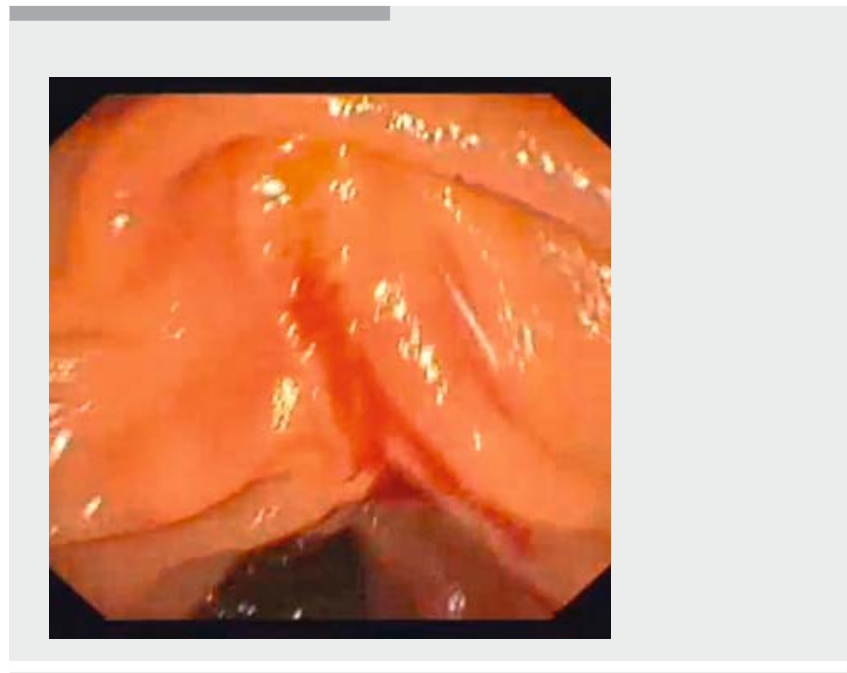

Video 1 This video presents a case with a spot diagnosis of upper gastrointestinal bleeding.

\section{Competing interests}

None

\section{References}

[1] Lower WE, Farrell JI. Aneurysm of the splenic artery. Report of a case and review of literature. Arch Surg 1931; 23: 182-190

[2] Sandblom P. Gastrointestinal hemorrhage through the pancreatic duct. Ann Surg 1970; 171: $61-66$

[3] Vimalraj V, Kannan DG, Sukumar R et al. Haemosuccus pancreaticus: diagnostic and therapeutic challenges. HPB (Oxford) 2009; 11: 345 350

[4] Rammohan A, Palaniappan R, Ramaswami S et al. Hemosuccus pancreaticus: 15 -Year experience from a tertiary care gi bleed centre. ISRN Radiol 2013; 2013: 191794

[5] Pham KD, Pedersen G, Halvorsen $\mathrm{H}$ et al. Usefulness of endoscopic ultrasound for the diagnosis of hemosuccus pancreaticus. Endoscopy 2014; 46: (Suppl. 01): E528 